\title{
Identification of Magnetic Phases in LC200N Steel by Backscattering Mössbauer Spectrometry
}

\author{
L. PAŠTeKA ${ }^{a, *}$, M. Miglierini ${ }^{b, c}$ AND M. Bujdoś $\check{~}^{a}$ \\ ${ }^{a}$ Institute of Laboratory Research on Geomaterials, Faculty of Natural Sciences, Comenius University in Bratislava, \\ Ilkovičova 6, 84215 Bratislava, Slovakia \\ ${ }^{b}$ Slovak University of Technology in Bratislava, Faculty of Electrical Engineering and Information Technology, \\ Institute of Nuclear and Physical Engineering, Ilkovičova 3, 81219 Bratislava, Slovakia \\ ${ }^{c}$ Department of Nuclear Reactors, Czech Technical University in Prague, \\ V Holešovičkách 2, 18000 Prague, Czech Republic
}

\begin{abstract}
In this paper we identified iron phases in three different samples of highly corrosion-resistant steel LC200N using the Mössbauer spectrometry which is particularly suited method for this purpose. Special emphasis is put upon magnetically active crystalline phases. The samples had different thermal history: (1) hardened, (2) hardened with consequent rapid quenching in liquid nitrogen, (3) non-hardened and prepared in a disc form with two sides ("as cut" and polished). Both ferritic magnetic phases and non-magnetic austenite phase were found in these samples. Relative content ratios between these phases were determined for each type of the samples and their respective sides. Higher amount of magnetic phases was found in non-hardened sample and on polished sides of all samples in general. The elemental characterization was accomplished by neutron activation analysis.
\end{abstract}

DOI: 10.12693/APhysPolA.131.1078

PACS/topics: 81.40.Ef, 76.80.+y, 81.65.Ps, 33.45.+x

\section{Introduction}

There is a tendency to develop and study steels and namely corrosion-resistant steels because of their possible applications in nuclear industry as construction materials for nuclear reactors and other components. In these industrial applications the materials are exposed to extreme conditions such as high temperature and pressure, intense radiation, highly corrosive environment, etc. These conditions can change their properties and have impact on the ability of long and safe operation of reactors [1].

Austenitic steels are used for reparation or replacement of human body parts and that is why plasma nitrided coatings have spread out to decrease the corrosion effects [2, 3]. Szymański et al. [4] performed fretting experiments with an austenitic pin on a martensitic disc. Observed superparamagnetic properties indicate high defection of the crystal structures of the Fe-oxides produced during fretting [4]. Characterization of structural and magnetic properties of martensitic Maraging-350 steel was performed by Nunes et al. [5]. This steel material is a soft ferromagnetic and residual induction and coercive field increase linearly with the maximum applied field of a minor loop until 250 Oe. Both magnetic parameters show an asymptotical tendency beyond this value (250 Oe) [5].

\section{Materials and methods}

${ }^{57} \mathrm{Fe}$ Mössbauer spectrometry (MS) with a conventional constant acceleration spectrometer was used with

*corresponding author; e-mail: pashty89@gmail.com a ${ }^{57} \mathrm{Co} / \mathrm{Rh}$ source in less common backscattering geometry. This method is very suitable for identification of nonmagnetic, paramagnetic, and ferromagnetic iron phases in thick samples. Contrary to conversion electron or conversion X-ray Mössbauer spectrometry, here $14.4 \mathrm{keV}$ gamma photons emitted from the absorber during its deexcitation are registered. Because their escape depth is $\approx 40 \mu \mathrm{m}$ an extensive volume of the sample is screened.

LC200N is highly nitrogenated corrosion-resistant alloyed steel used in very corrosive environment and produced by Zapp Materials Engineering, GmbH. Discshaped samples with $25 \mathrm{~mm}$ diameter and $0.5 \mathrm{~mm}$ thickness were cut from original rods by brass wire electric discharge machining. One side of the disks was polished in order to get rid of the residuals from the cutting procedure. Henceforth, the sides of the discs will be denoted as the "as-cut" and "polished" side. Three types of samples were investigated: (1) hardened, (2) hardened with consequent rapid quenching in liquid nitrogen, and (3) non-hardened.

Chemical composition of the steel was checked by neutron activation analysis (NAA) using the school reactor VR-1 operated at a power of $10^{8} \mathrm{cps}$ during $51 \mathrm{~min}$. Subsequent gamma spectrometry analysis was accomplished with an HPGe detector and Genie 2000 evaluation software.

\section{Results and discussion}

In order to look for possible occurrence of trace elements in the investigated steel we have performed NAA experiments. The obtained results are listed in Table I.

Presence of $\mathrm{Zn}, \mathrm{Cu}$ is due to brass cutting wire, As and $\mathrm{Na}$ are assigned to the residuals from the cutting procedure. It is noteworthy that different absorption cross- 
sections for thermal neutrons may result in identification of trace elements with very low abundance (e.g., $\left.{ }^{187} \mathrm{~W}\right)$.

Results of the neutron activation analysis.

TABLE I

\begin{tabular}{|c|c|c|c|}
\hline Radionuclide & Halftime & Reaction & Material \\
\hline${ }^{59} \mathrm{Fe}$ & $44.5 \mathrm{~d}$ & ${ }^{58} \mathrm{Fe}(\mathrm{n}, \gamma){ }^{59} \mathrm{Fe}$ & \\
\hline${ }^{51} \mathrm{Cr}$ & $27.7 \mathrm{~d}$ & ${ }^{50} \mathrm{Cr}(\mathrm{n}, \gamma){ }^{51} \mathrm{Cr}$ & \\
\hline${ }^{99} \mathrm{Mo}$ & $66 \mathrm{~h}$ & ${ }^{98} \mathrm{Mo}(\mathrm{n}, \gamma){ }^{99} \mathrm{Mo}$ & पै \\
\hline${ }^{187} \mathrm{~W}$ & $24 \mathrm{~h}$ & ${ }^{186} \mathrm{~W}(\mathrm{n}, \gamma){ }^{187} \mathrm{~W}$ & \\
\hline${ }^{54} \mathrm{Mn}$ & $312.1 \mathrm{~d}$ & ${ }^{54} \mathrm{Fe}(\mathrm{n}, \mathrm{p}){ }^{54} \mathrm{Mn}$ & ప్ \\
\hline${ }^{56} \mathrm{Mn}$ & $2.6 \mathrm{~h}$ & ${ }^{56} \mathrm{Fe}(\mathrm{n}, \mathrm{p}){ }^{56} \mathrm{Mn}$ & \\
\hline${ }^{60} \mathrm{Co}$ & $1925.3 \mathrm{~d}$ & ${ }^{60} \mathrm{Ni}(\mathrm{n}, \mathrm{p}){ }^{60} \mathrm{Co}$ & \\
\hline${ }^{69 m} \mathrm{Zn}$ & $13.76 \mathrm{~h}$ & ${ }^{68} \mathrm{Zn}(\mathrm{n}, \gamma)^{69 m} \mathrm{Zn}$ & \\
\hline${ }^{64} \mathrm{Cu}$ & $12.7 \mathrm{~h}$ & ${ }^{63} \mathrm{Cu}(\mathrm{n}, \gamma){ }^{64} \mathrm{Cu}$ & 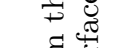 \\
\hline${ }^{76} \mathrm{As}$ & $1.1 \mathrm{~d}$ & ${ }^{75} \mathrm{As}(\mathrm{n}, \gamma){ }^{76} \mathrm{As}$ & 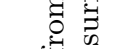 \\
\hline${ }^{24} \mathrm{Na}$ & $15 \mathrm{~h}$ & ${ }^{23} \mathrm{Na}(\mathrm{n}, \gamma){ }^{24} \mathrm{Na}$ & \\
\hline
\end{tabular}

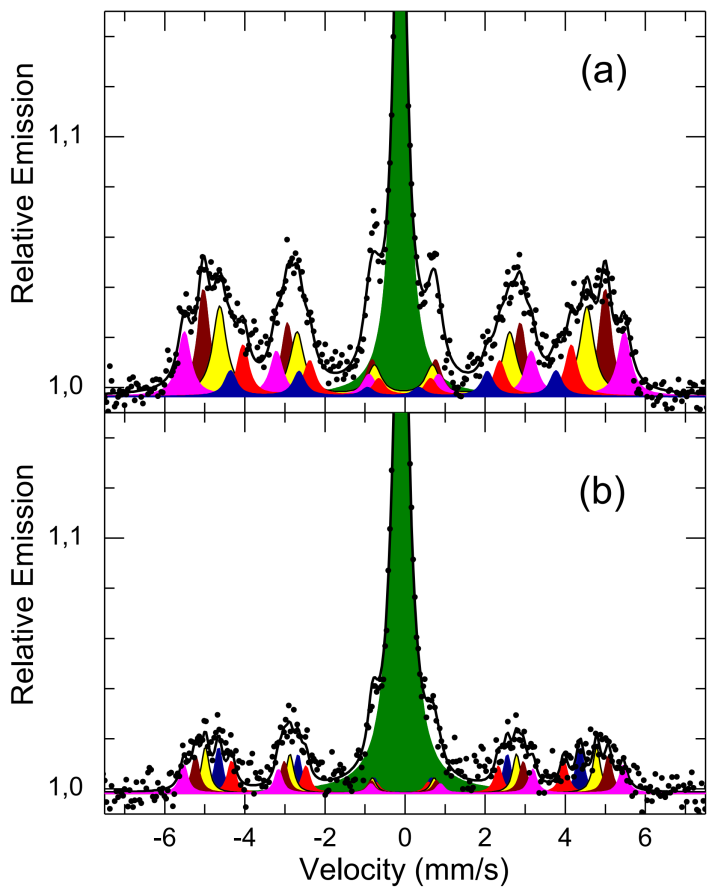

Fig. 1. Mössbauer spectrum of the hardened steel. Polished side (a) and "as cut" side (b).

Identification of magnetic and non-magnetic phases in the investigated alloy was performed by ${ }^{57} \mathrm{Fe}$ backscattering Mössbauer spectrometry. The former are represented by sextets while the latter shows a singlet Mössbauer line as shown for hardened (Fig. 1) and hardened steel with subsequent quenching (Fig. 2), respectively.

On the "as cut" side of the both hardened and hardened with subsequent quenching samples (Fig. $1 \mathrm{~b}$ and $2 \mathrm{~b}$ ), the amount of non-magnetic austenitic singlet is higher than on the polished side (Fig. 1a and 2a). It is possible that the polishing process removes some amount of austenite from the near surface regions.

The Mössbauer spectrum of the non-hardened steel in Fig. 3b recorded from the "as-cut" side is similar to those

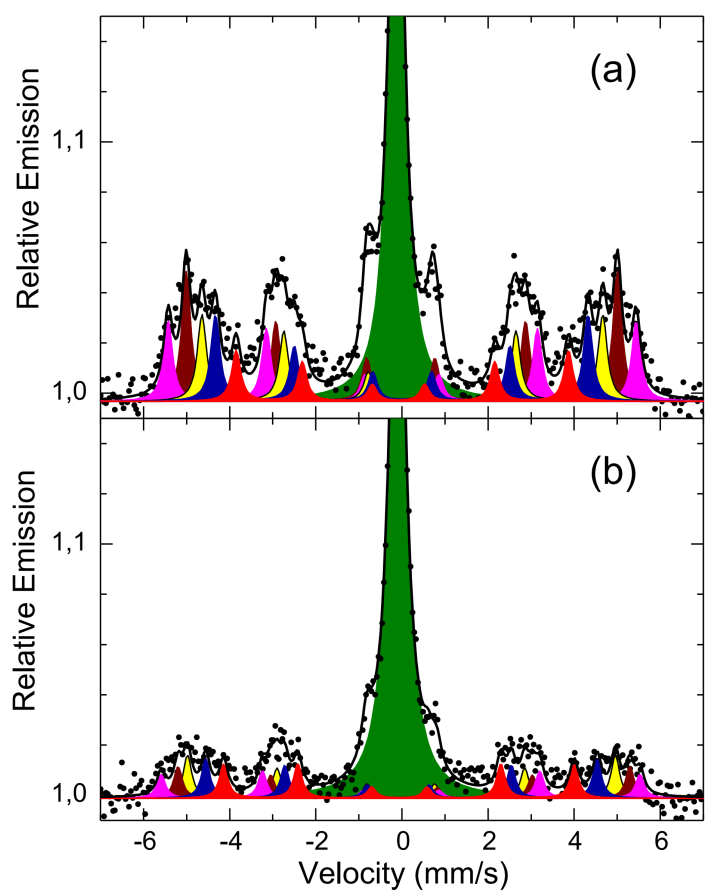

Fig. 2. Mössbauer spectrum of the hardened steel with quenching. Polished side (a) and "as cut" side (b).

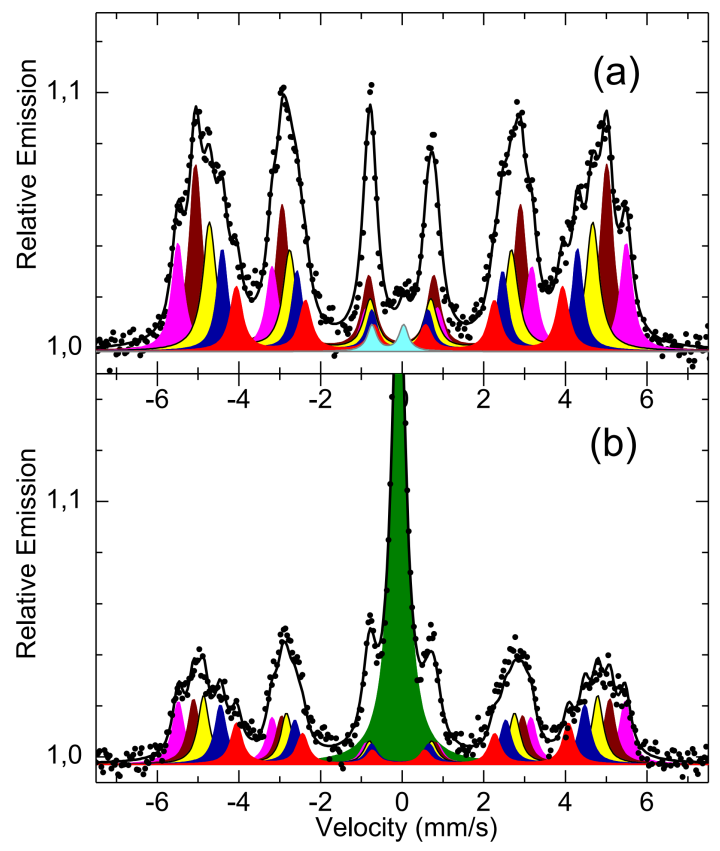

Fig. 3. Mössbauer spectrum of the non-hardened steel. Polished side (a) and "as cut" side (b).

from the previous samples. Nevertheless, the spectrum taken from its polished side is notably different from the other two because it exhibits high content of magnetic phases as seen in Fig. 3a.

Quantitative analysis of the content of non-magnetic and magnetic phases that are represented by singlet and sextets, respectively, is provided in Table II. 


\section{TABLE II}

Singlet or doublet/sextets ratios for all samples. Treatment: A - non-hardened, B - hardened, C - hardened and quenched, a — polished, b — "as cut".

\begin{tabular}{l|c|c|c|c|c|c}
\hline \hline & \multicolumn{2}{|c|}{ A } & \multicolumn{2}{c|}{ B } & \multicolumn{2}{c}{ C } \\
\cline { 2 - 7 } & $\mathrm{a}$ & $\mathrm{b}$ & $\mathrm{a}$ & $\mathrm{b}$ & $\mathrm{a}$ & $\mathrm{b}$ \\
\hline singlet\% & - & $34 \pm 1$ & $31 \pm 1$ & $60 \pm 1$ & $37 \pm 1$ & $62 \pm 1$ \\
doublet\% & $2 \pm 1$ & - & - & - & - & - \\
sextets\% & $98 \pm 1$ & $66 \pm 1$ & $69 \pm 1$ & $40 \pm 1$ & $63 \pm 1$ & $38 \pm 1$
\end{tabular}

It is noteworthy that a doublet spectral component was revealed in the non-hardened steel at the polished side of the disc. It is assigned to the inclusions of $\mathrm{Cu}$ and $\mathrm{Zn}$ from the cutting procedure. Its presence in the other samples might be hindered by very intensive central singlet.

The Mössbauer spectra for both hardened samples are very similar which means that quenching after hardening has only a small influence on the steel properties. On the other hand, there are significant differences between spectra of the non-hardened steel and both hardened steels especially at the polished side. Here, no singlet signal is seen and only sextets characteristic for magnetic phases are dominant. Parameters of hyperfine magnetic fields of the sextets are summarised in Table III. Colours in the $B_{h f}$ column correspond to those of individual sextet components plotted in Fig. 1-3. Isomer shifts of the individual sextets are from the range $-0.66 \div 0.02 \mathrm{~mm} / \mathrm{s}( \pm 0.02 \mathrm{~mm} / \mathrm{s})$, quadrupole shifts are from range $-0.6 \div 0.10 \mathrm{~mm} / \mathrm{s}( \pm 0.04 \mathrm{~mm} / \mathrm{s})$.

TABLE III

Hyperfine magnetic fields $B_{h f}[\mathrm{~T}]$ of the sextets. Experimental errors are of \pm 0.15 T. Symbols as in Table II.

\begin{tabular}{l|c|c|c|c|c|c}
\hline \hline \multirow{2}{*}{$B_{h f}$} & \multicolumn{2}{|c|}{$\mathrm{A}$} & \multicolumn{2}{c|}{$\mathrm{B}$} & \multicolumn{2}{c}{$\mathrm{C}$} \\
\cline { 2 - 7 } & $\mathrm{a}$ & $\mathrm{b}$ & $\mathrm{a}$ & $\mathrm{b}$ & $\mathrm{a}$ & $\mathrm{b}$ \\
\hline $\mathrm{S} 1$ & 34.1 & 34.1 & 33.8 & 33.6 & 34.1 & 34 \\
\hline $\mathrm{S} 2$ & 31.2 & 32 & 31.1 & 32.8 & 31.1 & 31.7 \\
\hline S3 & 28.5 & 30.3 & 28.9 & 30.9 & 29.2 & 29.9 \\
\hline $\mathrm{S} 4$ & 25.5 & 28 & 26.8 & 28.3 & 27.0 & 27.7 \\
\hline S5 & 25.2 & 25.8 & 23.9 & 25.3 & 24.8 & 25.3
\end{tabular}

\section{Conclusions}

LC200N steel was investigated by the Mössbauer spectrometry and NAA. The highest amount of ferritic ferromagnetic phases was found in the non-hardened sample. Its contribution is dominant on the polished side of the disc. Non-magnetic austenite is present in hardened and hardened/quenched samples with similar singlet to sextet ratios. There is no significant influence of quenching on steel properties. The doublet signal could be from impurities (brass wire) and occurs only in the polished non-hardened sample. These doublet-like paramagnetic signals are probably in all spectra but they are overlaid by strong signals of the central singlet. The polishing process reduces the amount of non-magnetic austenite presumably by local heat treatment.

\section{Acknowledgments}

This work was supported by the projects GACR 1412449S, VEGA 1/0182/16, VEGA 1/0203/14.

\section{References}

[1] J. Haščík, J. Lipka, L. Kupča, V. Slugeň, M. Miglierini, R. Gröne, I. Tóth, K. Vitázek, Acta Phys. Slov. 45, 37 (1995).

[2] M. Olzon-Dionysio, S.D. de Souza, R.L.O. Basso, S. de Souza, Surf. Coat. Technol. 202, 3607 (2008).

[3] S.D. de Souza, M. Olzon-Dionysio, R.L.O. Basso, S. de Souza, Mater. Character. 61, 992 (2010).

[4] K. Szymański, W. Olszewski, D. Satula, K. Rećko, J. Waliszewski, B. Kalska-Szostko, J.R. Dabrowski, J. Sidun, E. Kulesza, Wear 300, 90 (2013).

[5] G.C.S. Nunes, P.W.C. Sarvezuk, V. Biondo, M.C. Blanco, M.V.S. Nunes, A.M.H. de Andrade, A. Paesano Jr., J. Alloys Comp. 646, 321 (2015). 